Article

\title{
Hydrogen Sensing Performance of ZnO Schottky Diodes in Humid Ambient Conditions with PMMA Membrane Layer
}

\author{
Soohwan Jang ${ }^{1}$, Sunwoo Jung ${ }^{1}$ and Kwang Hyeon Baik ${ }^{2, *}$ \\ 1 Department of Chemical Engineering, Dankook University, Yongin 16890, Korea; \\ jangmountain@dankook.ac.kr (S.J.); cmkoung12@dankook.ac.kr (S.J.) \\ 2 Department of Materials Science and Engineering, Hongik University, Sejong 30016, Korea \\ * Correspondence: khbaik@hongik.ac.kr
}

Received: 31 December 2019; Accepted: 31 January 2020; Published: 4 February 2020

check for updates

\begin{abstract}
Enhanced hydrogen sensing performance of Pt Schottky diodes on $\mathrm{ZnO}$ single crystal wafers in humid ambient conditions is reported using a polymethylmethacrylate (PMMA) membrane layer. $\mathrm{ZnO}$ diode sensors showed little change in forward current when switching to wet ambient $\mathrm{H}_{2}$ conditions with $100 \%$ relative humidity. This sensitivity drop in the presence of water vapor can be attributed to surface coverage of hydroxyl groups on the Pt surface in humid ambient conditions. The hydrogen sensitivity of PMMA-coated diode sensors recovered up to $805 \%$ in wet $\mathrm{H}_{2}$ ambient conditions at room temperature. The PMMA layer can selectively filter water vapor and allow $\mathrm{H}_{2}$ molecules to pass through the membrane layer. It is clear that the PMMA layer can effectively serve as a moisture barrier because of low water vapor permeability and its hydrophobicity. In both dry and wet conditions, $\mathrm{ZnO}$ diodes exhibited relatively fast and stable on/off switching in each cycle with good repeatability.
\end{abstract}

Keywords: gas sensor; ZnO; humidity; hydrogen; Schottky diode

\section{Introduction}

Gas sensors based on metal oxide (MOX) semiconductors have been widely used for toxic gas detection and quality air control. Extensive efforts have been devoted to developing highly sensitive, selective, reliable, stable, and low-cost sensors [1-7]. Various $\mathrm{MOXs}$ such as $\mathrm{SnO}_{2}, \mathrm{TiO}_{2}, \mathrm{ZnO}, \mathrm{WO}_{3}$, $\mathrm{NiO}$, and $\mathrm{Ga}_{2} \mathrm{O}_{3}$ have shown significant change in the conductance through surface interaction and charge transfer between gas molecules and oxide surface atoms. Among those $\mathrm{MOXs}, \mathrm{ZnO}$ is highly promising for the potential use for gas sensors due to high conductance change, thermal and chemical stability, and facile synthesis into nanostructures having high surface-to-volume ratios [8-12]. Surface modification with $\mathrm{ZnO}$ nanorods and doping with specific dopants have yielded dramatic increases of its sensitivity and selectivity in gas sensor applications [13-15].

One of the most challenging issues for highly precise gas sensors is the selectivity, which detects the specific gas molecules under other reducing gas mixtures as well as in humid ambient conditions. In the presence of water vapor, $\mathrm{SnO}_{2}$-based gas sensors have shown the increased sensitivity as well as degraded sensor signals over a certain period of time [16-18]. The increase in operation temperature and the addition of select dopants were proposed to mitigate the effects of water on the sensitivity $[19,20]$. In the case of diode-based gas sensors, the sensitivity and selectivity were reported to be severely degraded in humid air conditions [21-23]. Under the exposure of water vapor, the surface-active sites for gas adsorption can be blocked by water molecules, thus resulting in the sensitivity drop in the presence of water vapor. There are rapidly growing demands for stable gas sensors to detect a 
small amount of hydrogen in extreme conditions, especially in hydrogen-fueled vehicles that require conditions above $50 \%$ relative humidity $(\mathrm{RH})$ at low temperatures to operate. Several methods have been proposed to solve the humidity problem in gas sensing, including polymer-based membrane layers such as polyvinyl fluoride, polytetrafluoroethylene, polymethylmethacrylate (PMMA), and polyimide, as well as inorganic membranes [24-27]. The permeability and its selectivity of polymer membrane are significantly influenced by various factors, such as the polarity of membrane materials, the degree of crystallization, and glass transition temperatures. Non-polar polymers exhibit a lower permeability to water vapor and polar gas molecules. Thus, a hydrophobic PMMA layer can serve as a selective filter due to its low permeability coefficient for moisture to water vapor by reducing water adsorption on the oxide surface. In this paper, we investigated the hydrogen sensing performance in high humidity conditions using PMMA protective layers directly coated on Pt/ZnO Schottky diode sensors.

\section{Materials and Methods}

The $5 \mathrm{~mm} \times 5 \mathrm{~mm} \mathrm{ZnO}$ single crystal substrates with the $c$-axis (0001) direction were purchased from a commercial supplier. Both substrates were double sided polished to a thickness of $0.5 \mathrm{~mm}$. Undoped $\mathrm{ZnO}$ substrates were characterized by scanning electron microscopy, atomic force microscope, and high-resolution $\mathrm{X}$-ray diffraction analysis. The root-mean-square roughness of the $\mathrm{ZnO}$ substrates was measured to be in the range of $1-5 \mathrm{~nm}$ with a scan size of $5 \times 5 \mu \mathrm{m}^{2}$. As can be seen in Figure 1 , the full width at half maximum of the X-ray rocking curve of the (0001) ZnO single crystal was measured to be 112 arcsec, indicating high crystalline quality. The electron carrier concentration of $\mathrm{ZnO}$ single crystal wafers was measured to be $\sim 5 \times 10^{17} \mathrm{~cm}^{-3}$. Ti/Al (20/100 $\left.\mathrm{nm}\right)$ metal layers were evaporated on $\mathrm{ZnO}$ substrates as Ohmic contact, formed by a photolithography and lift-off process. The Ohmic metallization was achieved by annealing at $300{ }^{\circ} \mathrm{C}$ for $1 \mathrm{~min}$ in ambient nitrogen in a rapid thermal annealer. Then, $200 \mathrm{~nm}$-thick $\mathrm{Si}_{3} \mathrm{~N}_{4}$ was deposited by plasma-enhanced chemical vapor deposition for the passivation layer. Wet etching with buffered HF solution was used for window opening for the active gas sensing surface. Schottky contact was formed by the evaporation of the catalytic Pt layer with $10 \mathrm{~nm}$ thickness. Ti/Au (20/100 nm) were evaporated on both Schottky and Ohmic contacts for metal probe pads. The current-voltage (I-V) characteristics were recorded using an Agilent 4155C semiconductor parameter analyzer (Agilent technologies, Santa Clara, CA, USA) under various $\mathrm{H}_{2}$ concentrations balanced with nitrogen. In order to prepare the PMMA protective layer on the device, PMMA with a molecular weight of 996,000 was dissolved in solvent (anisole) with a concentration of $40 \mathrm{mg} / \mathrm{mL}$, followed by mixing of the solution for $12 \mathrm{~h}$. PMMA was spin coated at $4000 \mathrm{rpm}$ for $30 \mathrm{~s}$, resulting in a thickness of $145 \mathrm{~nm}$. The morphologies of the PMMA surface and cross-section were observed using a scanning electron microscope, as shown in the author's previous literature [22]. The contact angle measurement for the PMMA dissolved in anisole on the Pt surface was $15.91^{\circ}$, whereas that on Si was $68.34^{\circ}$, clearly indicating that PMMA was more hydrophilic on the Pt layer. The hydrogen gas responses of Schottky diodes with and without PMMA membrane layers were measured when loaded in a gas test chamber with $4 \%$ dry $\mathrm{H}_{2}$ in ambient nitrogen. A water bubbler was utilized to produce wet ambient $\mathrm{H}_{2}$ for humidity conditions with $100 \% \mathrm{RH}$.

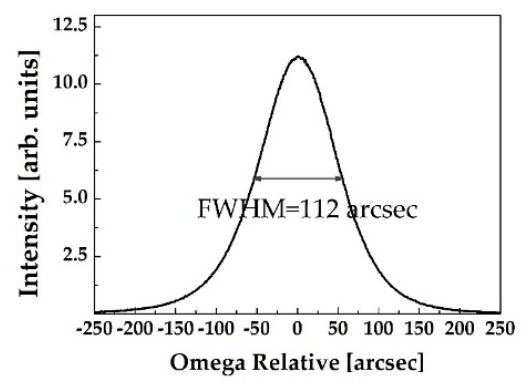

Figure 1. The relative $w$-rocking curve of $c$-plane (0001) $\mathrm{ZnO}$ single crystal wafer showing the full-width at half maximum (FWHM) value of 112 arcsec. 


\section{Results and Discussion}

Figure 2a shows the top-view optical microscope image of the fabricated Schottky barrier diode (SBD) on a $\mathrm{ZnO}$ single crystal wafer. Figure $2 \mathrm{~b}$ presents the schematic cross-section of the PMMA-coated diode on the catalytic Pt surface with Ohmic contact and $\mathrm{Si}_{3} \mathrm{~N}_{4}$ passivation layer.

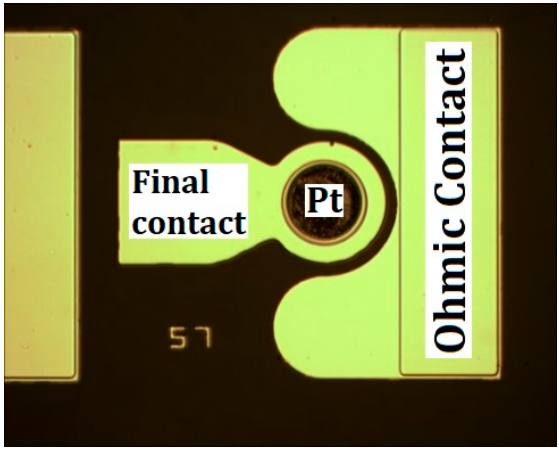

(a)

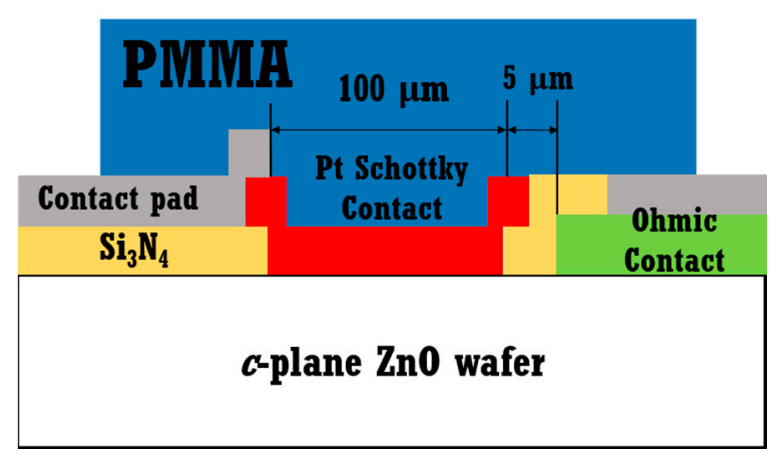

(b)

Figure 2. (a) Top-view optical microscope image of fabricated Schottky diode sensor; (b) cross-sectional schematic of polymethylmethacrylate (PMMA)-coated Pt/ZnO Schottky diode.

Figure 3a shows current-voltage (I-V) characteristics in-log scale of $\mathrm{Pt} / \mathrm{ZnO}$ Schottky barrier diodes (SBD) before and after $4 \% \mathrm{H}_{2}$ exposure in dry ambient as well as in wet ambient conditions. As clearly seen in Figure $3 \mathrm{~b}$ of $\mathrm{I}-\mathrm{V}$ curves in linear scale, $\mathrm{Pt} / \mathrm{ZnO}$ SBDs exhibited excellent response to hydrogen at room temperature. Under $\mathrm{H}_{2}$ exposure, hydrogen gas molecules adsorbed on the $\mathrm{Pt}$ catalytic layer, thus leading to the increase in forward current by reducing the effective Schottky barrier height (SBH). When switching to wet ambient conditions (100\% RH), little change in forward current was observed upon $\mathrm{H}_{2}$ gas exposure. This sensitivity drop in the presence of water vapor can be attributed to surface coverage of hydroxyl groups on the Pt surface in humid ambient conditions. As water vapor chemisorbed on the Pt catalytic surface, it resulted in the decrease of surface adsorption sites available for hydrogen. The cross-sensitivity toward water vapor has been well reported in $\mathrm{SnO}_{2}$-based MOX gas sensors [18-20]. Water vapor has been shown not only to decrease the resistance of $\mathrm{SnO}_{2}$-based materials, but also to significantly interfere with most target gases, resulting in the selectivity issues of gas sensors in humid air.

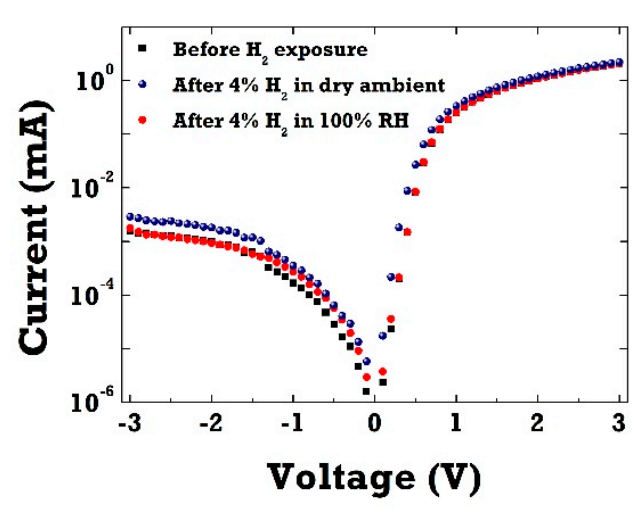

(a)

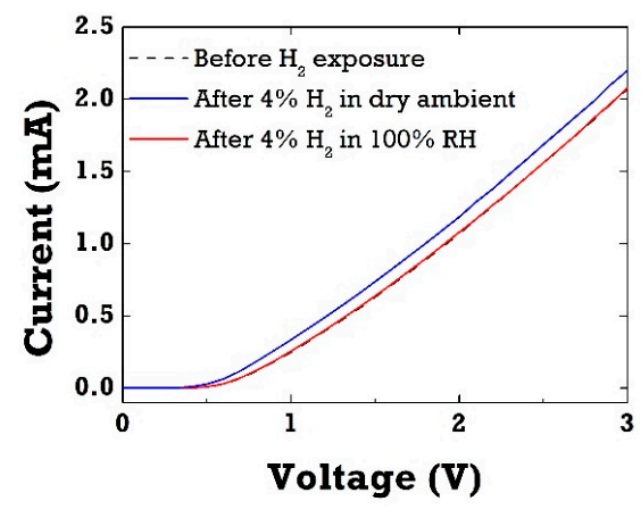

(b)

Figure 3. (a) Current-voltage (I-V) curve of $\mathrm{ZnO}$ diodes in log-scale before and after $4 \%$ hydrogen exposure in dry and wet ambient conditions; (b) corresponding I-V characteristics of $\mathrm{ZnO}$ diodes in linear-scale before and after $4 \%$ hydrogen exposure in dry and wet ambient conditions. 
Figure $4 \mathrm{a}$ shows the I-V characteristics of $\mathrm{Pt} / \mathrm{ZnO}$ SBD diodes with the PMMA membrane layer before and after $4 \% \mathrm{H}_{2}$ exposure in wet ambient conditions ( $\mathrm{RH} 100 \%$ ). The hydrogen sensitivity of PMMA-coated diode sensors in wet $\mathrm{H}_{2}$ almost recovered to the same level with the one in dry $\mathrm{H}_{2}$ ambient conditions. The relative current change for PMMA-coated diode sensors reached the maximum value of $805 \%$ in wet $\mathrm{H}_{2}$ ambient conditions at room temperature. The PMMA layer performed well in $\mathrm{ZnO}$ SBDs as a membrane layer, which selectively blocked water molecules, as previously reported by the authors [21,22]. Figure $4 \mathrm{~b}$ presents the transient change in SBH of Pt/ZnO SBDs in dry $\mathrm{H}_{2}$ and PMMA-coated $\mathrm{Pt} / \mathrm{ZnO}$ diodes in wet $\mathrm{H}_{2}$ ambient conditions. Note that the $\mathrm{SBH}$ values were extracted from the I-V curves using the thermionic emission model. The SBH changes were measured to be 72-75 meV for both SBD diodes upon exposure to hydrogen. After switching back to ambient nitrogen, the SBH of PMMA-coated diodes showed faster recovery.

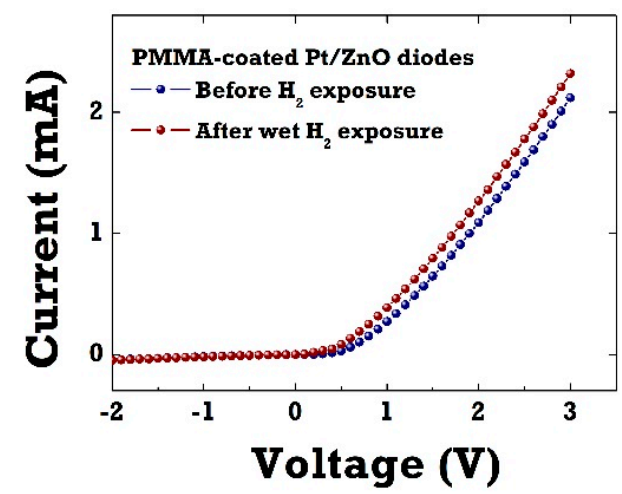

(a)

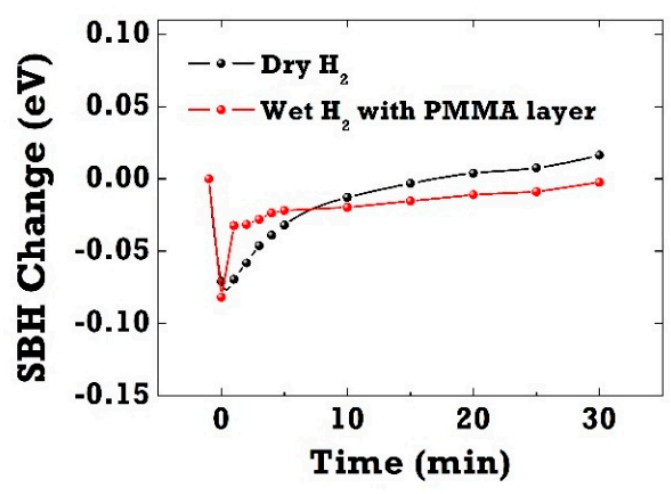

(b)

Figure 4. (a) I-V characteristics of PMMA-coated Pt/ZnO SBDs before and after wet $4 \%$ hydrogen exposure; (b) the transient change in Schottky barrier height (SBH) of Pt/ZnO SBDs in dry $\mathrm{H}_{2}$ and PMMA-coated $\mathrm{Pt} / \mathrm{ZnO}$ diodes in wet $\mathrm{H}_{2}$ ambient conditions.

Figure 5 shows the relative current change $(\Delta \mathrm{I})$ in percentage of PMMA-coated Pt/ZnO SBDs with and without the PMMA membrane layer upon exposure to $4 \% \mathrm{H}_{2}$ in dry and wet ambient conditions $(100 \%$ RH). Clearly, the SBD diodes without any protective layer exhibited only a negligible current response to $4 \% \mathrm{H}_{2}$ in wet conditions ( $\mathrm{RH} 100 \%$ ). This $\mathrm{H}_{2}$ sensitivity drop in the presence of water vapor can be attributed to surface coverage of hydroxyl groups on the Pt surface in humid ambient conditions. As water vapor chemisorbed on the Pt catalytic surface, it resulted in the decrease of surface adsorption sites available for hydrogen. It suggests that there is competition and strong interference between water vapor and $\mathrm{H}_{2}$ for the active adsorption sites. The sensitivity, the relative current change as a percentage, is defined as $\Delta \mathrm{I}\left[\left(\mathrm{I}_{H_{2}}-\mathrm{I}_{N_{2}}\right) / \mathrm{I}_{N_{2}}\right]$ in percentage where $\mathrm{I}_{H_{2}}$ and $\mathrm{I}_{N_{2}}$ denote diode currents measured in $\mathrm{H}_{2}$ and $\mathrm{N}_{2}$ ambient, respectively. The water-induced effect has been well established in metal oxide-based gas sensors. Water vapor has been shown not only to decrease the resistance of $\mathrm{SnO}_{2}$-based materials, but also to significantly interfere with most target gases, resulting in selectivity issues of gas sensors in humid air. In contrast, PMMA-coated SBD diodes demonstrated little change in sensitivity up to $800 \%$ at $0.2 \mathrm{~V}$ in high humid condition. The PMMA layer can selectively filter water vapor and allow $\mathrm{H}_{2}$ molecules to pass through the membrane layer. $\mathrm{H}_{2}$ molecules with small kinetic diameter $(2.89 \AA)$ can permeate easily thorough the PMMA layer when compared with other gases, such as $\mathrm{CO}_{2}(3.3 \AA), \mathrm{N}_{2}(3.64 \AA)$, and $\mathrm{CH}_{4}(3.8 \AA)$. 


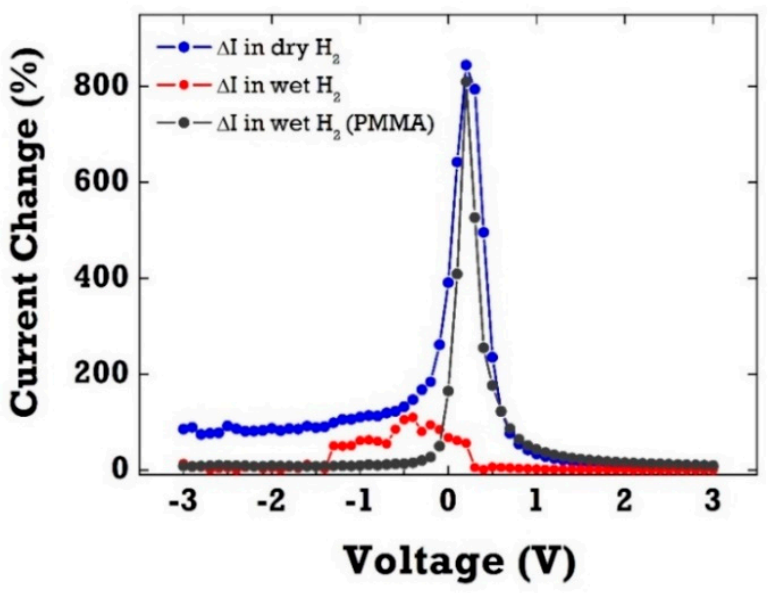

Figure 5. The current change as a function of bias voltage of $\mathrm{ZnO}$ diode sensors with and without the PMMA membrane layer in dry and wet $\mathrm{H}_{2}$ exposure. $\mathrm{H}_{2}(4 \%)$ was injected into the gas chamber for $30 \mathrm{~s}$.

Figure 6a shows the cyclic response of the $\mathrm{Pt} / \mathrm{ZnO}$ Schottky diode upon switching $4 \% \mathrm{H}_{2}$ on and off in dry and wet ambient conditions. One can see a dramatic decrease in forward currents in wet $\mathrm{H}_{2}$ ambient conditions measured at $0.2 \mathrm{~V}$ at room temperature. The inset figures show the negligible current response to hydrogen in the range of a few nA. It suggests that there would be competition and strong interference between water vapor and $\mathrm{H}_{2}$ for the adsorption sites. Water molecules significantly interfere with most target gases, resulting in the selectivity issues of gas sensors in humid air. In the case of PMMA-coated diodes, the hydrogen sensitivity in wet $\mathrm{H}_{2}$ recovered to the same level in dry $\mathrm{H}_{2}$ ambient conditions as can be seen in Figure 6b. Clearly, the PMMA layer could effectively act as effective moisture barrier because of low water vapor permeability. In both dry and wet conditions, SBD diodes exhibited relatively fast and stable on/off switching in each cycle with good repeatability.

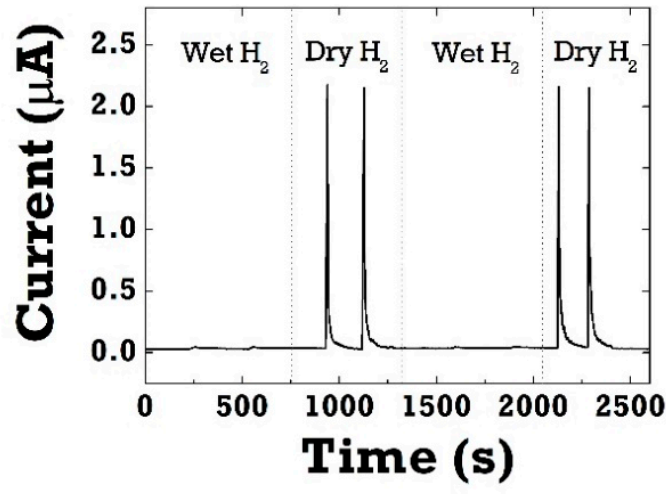

(a)

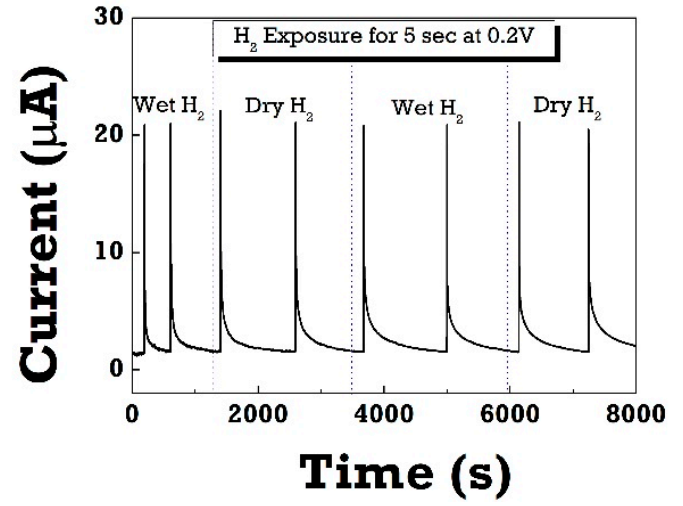

(b)

Figure 6. (a) Cyclic response curves of $\mathrm{Pt} / \mathrm{ZnO}$ diode sensors without PMMA layer; (b) cyclic response curves of PMMA-coated $\mathrm{Pt} / \mathrm{ZnO}$ diode sensors, which were measured at $0.2 \mathrm{~V}$ forward voltage when switching $\mathrm{H}_{2}$ on and off in dry and wet ambient conditions. The same level of sensitivity was observed in PMMA-coated diode sensors even in repeated cycles of switching dry and wet $\mathrm{H}_{2}$ ambient conditions in $100 \% \mathrm{RH}$.

\section{Conclusions}

$\mathrm{Pt} / \mathrm{ZnO}$ Schottky diode sensors showed a drastic decrease of hydrogen sensitivity in the presence of water vapor. This sensitivity drop in the presence of water vapor resulted from the surface coverage of hydroxyl groups on the Pt surface, thus leading to the interference of surface adsorption sites 
available for hydrogen. By employing a PMMA membrane layer on the catalytic Pt surface, enhanced hydrogen sensing performance was achieved in humid ambient at room temperature. The hydrogen sensitivity up to $805 \%$ was measured in $100 \%$ relative humidity. The PMMA-coated diode sensors also showed stable sensor operation in repeated cycles of $\mathrm{H}_{2}$ on and off without any degradation. PMMA membrane layers can be effectively integrated on Pt surface of diode sensor and work as a selective filter of water molecules in humid ambient conditions.

Author Contributions: S.J. (Soohwan Jang) proposed the research idea and designed the experiments and contributed to revising and proofreading the article. S.J. (Sunwoo Jung) performed the experiments and analyzed the data. K.H.B. guided the experiments and analyzed the data and wrote the article. All authors have read and agreed to the published version of the manuscript.

Funding: This research was supported by the Basic Science Research Program through the National Research Foundation of Korea (NRF) funded by the Ministry of Education (2018R1D1A1A09083988, 2017R1D1A3B03035420), and Nano Material Technology Development Program through the National Research Foundation of Korea (NRF) funded by the Ministry of Science, ICT and Future Planning (2015M3A7B7045185). This present research was also supported by 2019 Hongik University Research Fund.

Conflicts of Interest: The authors declare no conflict of interest.

\section{References}

1. Wang, C.; Yin, L.; Zhang, L.; Xiang, D.; Gao, R. Metal oxide gas sensors: Sensitivity and influencing factors. Sensors 2010, 10, 2088-2106. [CrossRef] [PubMed]

2. Fine, G.F.; Cavanagh, L.M.; Afonja, A.; Binions, R. Metal oxide semi-conductor gas sensors in environmental monitoring. Sensors 2010, 10, 5469-5502. [CrossRef] [PubMed]

3. Liu, X.; Cheng, S.; Liu, H.; Hu, S.; Zhang, D.; Ning, H. A survey on gas sensing technology. Sensors 2012, 12, 9635-9665. [CrossRef]

4. Neri, G. First fifty years of chemoresistive gas sensors. Chemosensors 2015, 3, 1-20. [CrossRef]

5. Patil, S.J.; Patil, A.V.; Dighavkar, C.G.; Thakare, K.S.; Borase, R.Y.; Nandre, S.J.; Deshpande, N.G.; Ahire, R.R. Semiconductor metal oxide compounds based gas sensors: A literature review. Front. Mater. Sci. 2015, 9 , 14-37. [CrossRef]

6. Jiang, H.; Huang, M.; Yu, Y.; Tian, X.; Zhao, X.; Zhang, W.; Zhang, J.; Huang, Y.; Yu, K. Integrated Temperature and Hydrogen Sensors with MEMS Technology. Sensors 2018, 18, 94. [CrossRef] [PubMed]

7. Jiang, H.; Yu, Y.; Zhang, L.; Zhu, J.; Zhao, X.; Zhang, W. Flexible and Highly Sensitive Hydrogen Sensor Based on Organic Nanofibers Decorated by Pd Nanoparticles. Sensors 2019, 19, 1290. [CrossRef]

8. Anderson, T.; Ren, F.; Pearton, S.; Kang, B.S.; Wang, H.-T.; Chang, C.-Y.; Lin, J. Advances in hydrogen, carbon dioxide, and hydrocarbon gas sensor technology using GaN and ZnO-based devices. Sensors 2009, 9, 4669-4694. [CrossRef]

9. Wan, Q.; Li, Q.H.; Chen, Y.J.; Wang, T.H.; He, X.L.; Li, J.P.; Lin, C.L. Fabrication and ethanol sensing characteristics of ZnO nanowire gas sensors. Appl. Phys. Lett. 2004, 84, 3654-3656. [CrossRef]

10. Leonardi, S.G. Two-dimensional zinc oxide nanostructures for gas sensor applications. Chemosensors 2017, 5, 17. [CrossRef]

11. Chava, R.K.; Oh, S.-Y.; Yu, Y.T. Enhanced $\mathrm{H}_{2}$ gas sensing properties of $\mathrm{Au} @ \mathrm{In}_{2} \mathrm{O}_{3}$ core-shell hybrid metal-semiconductor heteronanostructures. CrystEngComm 2016, 18, 3655-3666. [CrossRef]

12. Majhi, S.M.; Rai, P.; Yu, Y.-T. Facile Approach to Synthesize Au@ZnO Core-Shell Nanoparticles and Their Application for Highly Sensitive and Selective Gas Sensors. ACS Appl. Mater. Interfaces 2015, 7, 9462-9468. [CrossRef] [PubMed]

13. Gurav, K.V.; Gang, M.G.; Shin, S.W.; Patil, U.M.; Deshmukh, P.R.; Agawane, G.L.; Suryawanshi, M.P.; Pawar, S.M.; Patil, P.S.; Lokhande, C.D.; et al. Gas sensing properties of hydrothermally grown ZnO nanorods with different aspect ratios. Sens. Actuators B Chem. 2014, 190, 439-445. [CrossRef]

14. Chang, J.; Ahmad, M.Z.; Wlodarski, W.; Waclawik, E.R. Self-assembled 3D ZnO porous structures with exposed reactive $\{0001\}$ facets and their enhanced gas sensitivity. Sensors 2013, 13, 8445-8460. [CrossRef]

15. Liu, X.; Zhang, J.; Wang, L.; Yang, T.; Guo, X.; Wu, S.; Wang, S. 3D hierarchically porous ZnO structures and their functionalization by au nanoparticles for gas sensors. J. Mater. Chem. 2011, 21, 349-356. [CrossRef] 
16. Ionescu, R.; Vancu, A.; Moise, C.; Tomescu, A. Role of water vapour in the interaction of $\mathrm{SnO}_{2}$ gas sensors with $\mathrm{CO}$ and $\mathrm{CH}_{4}$. Sens. Actuators B Chem. 1999, 61, 39-42. [CrossRef]

17. Ghiotti, G.; Chiorino, A.; Martinelli, G.; Carotta, M.C. Moisture effects on pure and Pd-doped $\mathrm{SnO}_{2} \mathrm{thick}$ films analysed by FTIR spectroscopy and conductance measurements. Sens. Actuators B Chem. 1995, 25, 520-524. [CrossRef]

18. Fukui, K.; Katsuki, A. Improvement of humidity dependence in gas sensor based on $\mathrm{SnO}_{2}$. Sens. Actuators B Chem. 2000, 65, 316-318. [CrossRef]

19. Itoh, T.; Matsubara, I.; Kadosaki, M.; Sakai, Y.; Shin, W.; Izu, N.; Nishibori, M. Effects of high-humidity aging on platinum, palladium, and gold loaded tin oxide-Volatile organic compound sensors. Sensors 2010, 10, 6513-6521. [CrossRef]

20. Kim, H.-R.; Haensch, A.; Kim, I.-D.; Barsan, N.; Weimar, U.; Lee, J.-H. The role of NiO doping in reducing the impact of humidity on the performance of $\mathrm{SnO}_{2}$-based gas sensors: Synthesis strategies, and phenomenological and spectroscopic studies. Adv. Funct. Mater. 2011, 21, 4456-4463. [CrossRef]

21. Baik, K.H.; Jung, S.; Ren, F.; Pearton, S.J.; Jang, S. Moisture insensitive PMMA coated Pt-AlGaN/GaN diode hydrogen sensor and its thermal stability. ECS J. Solid State Sci. Technol. 2018, 7, Q3009-Q3013. [CrossRef]

22. Jung, S.; Baik, K.H.; Ren, F.; Pearton, S.J.; Jang, S. Pt-AlGaN/GaN hydrogen sensor with water-blocking PMMA layer. IEEE Electron Dev. Lett. 2017, 38, 657-660. [CrossRef]

23. Bazylak, A. Liquid water visualization in PEM fuel cells: A review. Int. J. Hydrogen Energy 2009, 34, $3845-3857$. [CrossRef]

24. Graunke, T.; Schmitt, K.; Raible, S.; Wollenstein, J. Towards enhanced gas sensor performance with fluoropolymer membranes. Sensors 2016, 16, 1605. [CrossRef] [PubMed]

25. Sugimoto, I.; Nakamura, M.; Kuwano, H. Organic gas sorption by chemical-sensing fluoropolymer films prepared by radio-frequency sputtering. Thin Solid Films 1994, 249, 118-125. [CrossRef]

26. Samuel, J.J.S.; Ruther, P.; Frerichs, H.-P.; Lehmann, M.; Paul, O.; Rühe, J. A simple route towards the reduction of surface conductivity in gas sensor devices. Sens. Actuators B Chem. 2005, 110, 218-224. [CrossRef]

27. Jansen, J.C.; Clariziaa, G.; Bernardoa, P.; Bazzarellia, F.; Friessb, K.; Randováa, A.; Schauerc, J.; Kubickad, D.; Kacirkováe, M.; Izake, P. Gas transport properties and pervaporation performance of fluoropolymer gel membranes based on pure and mixed ionic liquids. Sep. Purif. Technol. 2013, 109, 87-97. [CrossRef] 